\title{
aniki
}

Revista Portuguesa da Imagem em Movimento Portuguese Journal of the Moving Image

\section{Casa tomada: O medo em El hombre de al lado (Gastón Duprat e Mariano Cohn, 2009) Natalia Christofoletti Barrenha ${ }^{1}$}

\begin{abstract}
Introdução ${ }^{2}$
As relações entre medo e experiência urbana guiarão este texto sobre o longa-metragem El hombre de al lado (Gastón Duprat e Mariano Cohn, 2009), no qual se destaca o medo como fator fundamental para engendrar pautas de segregação social e espacial e o outro como ser temido por excelência. Segundo Yi-fu Tuan (2005) e Zygmunt Bauman (2008), o medo está totalmente ligado à incerteza, à incompletude, à instabilidade, à estranheza, ao desequilíbrio, à imprevisibilidade e à sensação de fragilidade diante de tudo isso. $\mathrm{O}$ filme de Duprat e Cohn está embebido desses elementos de diversas formas, e a ressignificação constante - que mantém a incerteza, a instabilidade, etc. - é, nele, matéria corrente. O filme aprofunda ainda o tema do rompimento dos laços na sociedade urbana ao estender essa quebra ao interior da casa. A questão do viver junto e suas disputas cede lugar à emergência do estranho (segundo Freud) no familiar, que desloca progressivamente os objetos e objetivos do medo durante o longa-metragem. Proponho ainda algumas conexões entre o filme e dois contos clássicos da literatura argentina do século $\mathrm{XX}$, que se dedicaram a trabalhar de forma notável os temores das sociedades de seus tempos: "Casa tomada", de Julio Cortázar, e "Cabecita negra”, de Germán Rozenmacher.
\end{abstract}

Segundo o dicionário Priberam da Língua Portuguesa, o medo é um estado emocional resultante da consciência de perigo ou de ameaça (sendo estes reais, hipotéticos ou imaginários). Para María Milagros López (citada por Pastana 2003), o medo faz parte de nossa natureza, mas seus objetos são historicamente determinados - o medo é

\footnotetext{
${ }^{1}$ Universidade Estadual de Campinas (UNICAMP), Instituto de Estudos da Linguagem, Programa de Pós-Graduação em Teoria e História Literária, 13083-970, Brasil.

${ }^{2}$ Uma primeira aproximação a esse filme foi realizada pela autora no texto "(Des)encontros na cidade em El hombre de al lado (Gastón Duprat e Mariano Cohn, 2009)", apresentado no IV Congreso de la Asociación Argentina de Estudios de Cine y Audiovisual (AsAECA), realizado em março/2014 na Universidad Nacional de Rosario (Barrenha 2015, 352-357).
} 
realidade e representação. Na coletânea Ensaios sobre o medo (2007), o organizador Adauto Novaes também destaca como as formas do medo são oscilantes no tempo e no espaço, acrescentando que, no passado, o medo vinha mais da natureza e do sobrenatural, enquanto hoje, o principal medo da Humanidade vem do próprio homem afirmação complementada por Maria Rita Kehl e por Jean Delumeau, no volume editado por Novaes. Segundo Kehl, atualmente, toda a enorme variedade dos sentimentos do medo ficou encoberta pelo temor em relação a nossos semelhantes. Já Delumeau lembra que, ao lado das apreensões universais, que são parte do inconsciente coletivo (como o medo do mar ou da noite), ou daquelas inquietações motivadas por perigos concretos (como os desastres naturais e as epidemias), é preciso atentar aos medos mais culturais, como é o medo do outro. Segundo o autor, a alteridade nos assusta pela sua diferença, e não deixa de ser uma forma de medo do desconhecido.

Delumeau ainda refere algumas questões sobre a cidade e o medo: embora, para ele, seja uma banalidade dizer isso, hoje é, sobretudo, nas cidades (e, especialmente, nas grandes cidades) que se tem medo. É preciso lembrar que essa situação é contrária ao que prevaleceu durante muito tempo, já que o surgimento da cidade está ligado à necessidade de aplacar o fenômeno do medo, como nos explica Josepa Bru e Joan Vicente:

As origens da cidade como realidade e como conceito foram marcadas em grande (mas não única) medida pela necessidade dos grupos humanos de se sentirem seguros e, para isso, se gerou um espaço e umas estruturas sociais e de poder que a satisfizessem. Estabeleceuse uma relação "dentro-fora", com a muralha como limite real e metafórico, que fazia do espaço urbano um lugar de ordem. (2005, $15)^{3}$

Yi-fu Tuan (2005) e Zygmunt Bauman (2009) também ressaltam o paradoxo de as cidades serem vistas como lugares assustadores e associados ao perigo devido à relação fundacional entre cidade e proteção. Outro paradoxo que se dá é que, à medida que a cidade obriga à convivência e a definir políticas de integração das diferenças que frequentemente estão na origem da insegurança e do medo, ela se torna o único espaço capaz de mitigar verdadeiramente o medo sem renunciar a essa complexidade. Assim, segundo Bru e Vicente, a cidade é segura não por ser fechada, mas por ser um lugar de convivência.

Porém, como já foi comentado acima, o desconhecimento entre os sujeitos diversos causa desconfiança. Se a isso se unem imaginários estereotipados e o fomento da sensação de insegurança

\footnotetext{
${ }^{3}$ Tradução da autora. Todos os textos que não possuem edição em língua portuguesa foram traduzidos pela autora.
} 
por meio da amplificação midiática da criminalidade violenta, ${ }^{4}$ as suspeitas se multiplicam. Débora Regina Pastana (2003) aponta que o medo permite compreender algumas relações sociais, já que é um tipo de exteriorização cultural que, intencionalmente ou não, muda os valores de um grupo, aumentando ou diminuindo o grau de coesão entre os indivíduos.

Desse modo, o medo cria novas formas de usar a cidade, mais restritivas e defensivas, induzindo mudanças na vida cotidiana dos espaços urbanos em razão das medidas de controle. De um lado, as pessoas são orientadas a ter conduta alerta, prudente, vigilante, que mesura cada ato com o cuidado necessário para evitar riscos de sua vida e patrimônio, instituindo mudanças de hábito através das precauções aprendidas pelos cidadãos para a diminuição da vulnerabilidade. De outro, a materialização do medo toma distintas expressões com a (re)estruturação do espaço urbano e a adoção de uma "arquitetura do medo" composta por elementos como muros, grades, cercas, câmeras, privatização, alarmes e um longo etcétera. A cultura do medo propaga barreiras de sociabilidade e incrementa a segregação espacial, além de degenerar as relações sociais em face da desconfiança (Eckert e Rocha 2008).

\section{O homem [e o medo] ao lado}

Hugo Hortiguera (2014) nota que a situação de deterioração ou lassidão dos laços sociais é, talvez, um dos elementos que mais significativa e insistentemente vêm se projetando no discurso cinematográfico argentino da última década. Primeiro, o autor localiza como os filmes de Pablo Trapero, Adrián Caetano ou Marcelo Piñeyro coincidem em falar sobre as fragmentações do espaço urbano, ao mesmo tempo que aludem a âmbitos que deveriam ser refeitos ou reinventados, para que se possa reconstruir um lugar de encontro que hoje é de profunda disputa. Para esses diretores, os espaços urbanos têm perdido seu status como lugares de comunicação cultural e de interação social espontânea, se transformando em territórios quebrados, de crises contínuas e cheios de fendas.

Em seguida, Hortiguera percebe que um dos aspectos mais chamativos da cinematografia argentina nesse período radica na fuga

\footnotetext{
${ }^{4}$ Como afirma Gabriel Kessler, o sentimento de insegurança não é um mero reflexo dos índices de delito: "em geral aumenta quando se produz um incremento na criminalidade, mas uma vez instalado como problema social, não necessariamente decresce, ainda que as taxas de delito diminuam" $(2014,55)$. No mesmo sentido, Marcelo Lopes de Souza (2008) explica que a criminalidade violenta e a sensação de insegurança não necessariamente mantêm entre si uma relação linear - entre outros fatores, devido a uma mídia sensacionalista que trata de amplificar e distorcer estatísticas.
} 
da cidade. ${ }^{5}$ Convocando $X X Y$ (Lucía Puenzo, 2007), El último verano de la boyita (Julia Solomonoff, 2009), Las viudas de los jueves (Marcelo Piñeyro, 2010) e Dos hermanos (Daniel Burman, 2010), o autor observa como seus personagens abandonam a esfera urbana (Buenos Aires, especialmente) para se instalar de costas a ela, buscando um lugar bucólico ou quimérico. Não obstante, os conflitos alcançam esses supostos paraísos. Em muitos casos, percebe-se um recolhimento quase de forma autista e obsessiva na casa que aparece nos filmes como o último refúgio onde se proteger e escapar. Mas os conflitos também alcançam essa zona íntima: uma divisão parece ter possuído os espaços mais recônditos, e neles se instalou uma fissura que os converteu em lugares instáveis e inseguros (Hortiguera 2014). Outros exemplos citados pelo pesquisador são Cama adentro (Jorge Gaggero, 2004), Luna de Avellaneda (Juan José Campanella, 2004), ¿Quién dice que es fácil? (Juan Taratuto, 2007), Séptimo (Patxi Amezcua, 2013), Una semana solos (Celina Murga, 2008) e, especialmente, El hombre de al lado.

Hortiguera (2013, 2015) dedica vários textos ao filme de Duprat e Cohn, devido à maneira contundente com que o longametragem toca a questão da casa como espaço íntimo fraturado, onde se torna impossível manejar conflitos. A dissolução dos laços sociais que revela um tecido de desconfianças atinge a casa, que deixa de ser o lugar que provê proteção e sentido a seus habitantes para se transformar em mais um espaço instável e em permanente discórdia dentro da cidade.

No filme, o sofisticado arquiteto Leonardo Kachanovsky vive com sua esposa Ana, a filha adolescente Lola e a empregada Elba na também sofisticada Casa Curutchet, única obra de Le Corbusier na

\footnotetext{
${ }^{5}$ No artigo "Una nueva cartografía para el cine argentino", a crítica de cinema argentina Marcela Gamberini discutia a fuga da cidade em alguns dos mais destacados filmes da Competição Argentina do BAFICI (Buenos Aires Festival Internacional de Cine Independiente) de 2012, em sintonia com as considerações de Hortiguera: “(...) chama a atenção que três dos filmes mostrados pelo BAFICI nesta última edição trabalhem com tantos espaços abertos, territórios imensos. (...) Este espaço virgem, desabitado, inquietante (...) é o protagonista de Los salvajes, de Alejandro Fadel, de Germania, de Maximiliano Schonfeld, de La araña vampiro, de Gabriel Medina. Um espaço a recorrer, a transitar, um espaço vazio que lentamente se enche de corpos, de árvores, de rios, de violência, de casas, de enfrentamentos. (...) O recorrido desses exteriores, incomensuráveis e excessivos, é a prova que os personagens devem superar. (...) O verdadeiramente importante é o recorrido desses espaços, o transcorrer. O resultado desse caminhar, fugir, escapar, buscar é uma forte sensação de desorientação" (Gamberini 2012). Para a autora, esses filmes apresentavam uma nova maneira de narrar, já que esse espaço seria o protagonista e se conectava com a perda de sentido da urbanidade.
} 
América Latina. “ "A marretadas”, ele é obrigado a interagir com seu vizinho Víctor Chubelo através da janela - uma fronteira que os une e os separa, de acordo com a aceção de fronteira proposta por Andréa França:

Fronteira como linha demarcadora do idêntico, que limita, torna estável e mesmo enclausura um certo conjunto de valores e crenças, mas também lugar instável, de passagem e transição para o outro, o diferente. E ainda, fronteira como linha que se defronta com o estranho que habita o mais íntimo do território e o ameaça de dentro como o absolutamente exterior. $(2003,21)$

Víctor quer abrir uma janela para receber uns raios de sol, mas sua vista dá diretamente para a sala de Leonardo, o que dispara o conflito - no espaço íntimo dos Kachanovsky se instala um olhar invasivo que provoca medo, conforme a perceção do arquiteto, que compartilhamos. Buscando resolver a desavença, os homens se encontram para conversar, ora através da janela em construção, ora através de outras fronteiras, como o portão ou outra janela da Curutchet, ora fazendo Elba de passa-recado: em poucas ocasiões estão frente a frente sem algo que os "emoldure", que contorne os limites de cada um (Reis 2012). As diferenças entre ambos e os terrenos que habitam são constantemente marcados.
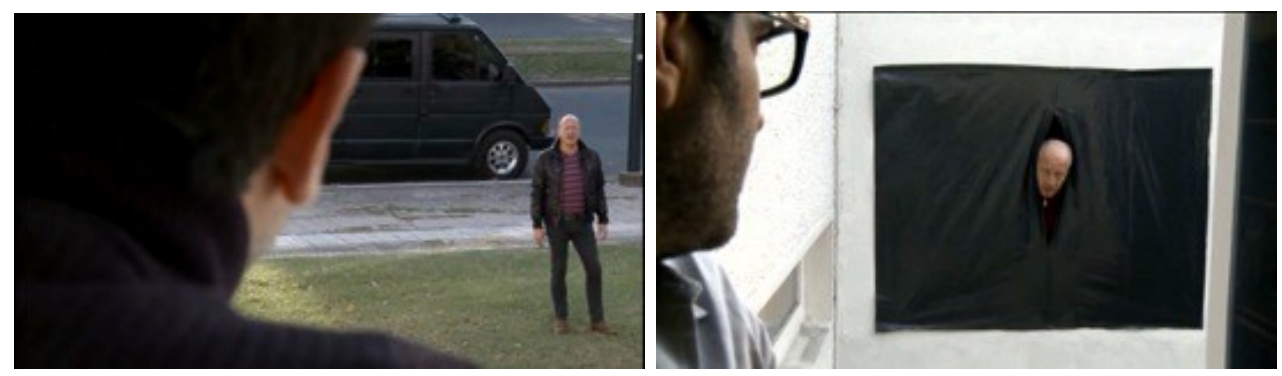

Imagens 1 e 2: El hombre de al lado (Gastón Duprat e Mariano Cohn, 2009) | (C) Aleph Media

Porém, na tentativa de expulsar essa "presença" assustadora que altera a rotina da família, Leonardo vai cruzando algumas dessas linhas - passando de vítima a algoz desajeitado. Primeiro, em busca do ruído que toma a casa, ou mergulhado em angústia, ele perambula pela residência, transformando-a em um labirinto que dificulta a

\footnotetext{
${ }^{6}$ A Casa Curutchet foi projetada por Le Corbusier em 1948 e edificada entre 1949 e 1953 em La Plata (cerca de $60 \mathrm{~km}$ ao sul de Buenos Aires). Encomendada ao arquiteto pelo médico Pedro Curutchet, a construção da casa teve muitos problemas e custou dez vezes mais que o planejado. Curutchet viveu aí com sua família por 12 anos, na década de 1960. Depois, o local esteve desocupado e esquecido, até que em 1988 uma fundação médica o alugou e, mais recentemente, o Colégio de Arquitetos da Província de Buenos Aires o utiliza como sede. Atualmente, há um projeto para expropriá-la e transformá-la em patrimônio público. É importante lembrar que La Plata foi uma das primeiras cidades do mundo (fundada em 1882) construída a partir de um plano urbanístico prévio, seguindo uma concepção racionalista dos centros urbanos em voga em fins do século XIX.
} 
mobilidade dos outros membros em seus interiores confusos, promovendo desencontros. A inquietação e o enervamento do arquiteto, sua obsessão por segurança, são muito mais perturbadores para a vivência na casa do que a interferência inesperada e chocante de Víctor. Posteriormente, reproduzindo e devolvendo, de maneira muito mais incisiva, o olhar lançado pelo homem ao lado.

Se os limites entre os personagens vão ficando cada vez mais difusos, os limites espaciais vão sendo endurecidos a partir da atitude de Leonardo - não só internamente. A Curutchet poderia ser considerada, como denominou Beatriz Colomina (1998, 127), uma "casa exibicionista". A autora apregoa que o que distingue a arquitetura do século XX é o papel central ocupado pela casa: por um lado, porque a casa foi o mais importante veículo de investigação para novas ideias na área; por outro, pela maneira como essas novas ideias são desenvolvidas em outros "espaços", como fotografias, publicações, exibições, congressos, feiras, revistas, jornais, museus, galerias de arte, competições, publicidades e computadores -, fazendo com que a casa se torne uma nova forma de espaço público.

A cidade nunca pôde ser separada do espaço doméstico. O que se passa na praça pública molda o espaço doméstico que parecia estar separado dela, e vice-versa. Mas no século XX, os dois campos privado e público - estão completamente misturados. Este entrelaçamento tem uma longa história. Eletricidade, equipamentos, novas tecnologias e materiais de construção, e novas formas de comunicação têm transformado radicalmente a casa. Do telefone ao rádio, à televisão, aos computadores, aos aparelhos de fax e ao email, a casa tem sido continuamente invadida, com o que é público e o que é privado interminavelmente renegociados. (Colomina 1998, 130)

Esse aspecto é claramente absorvido pelos moradores da Curutchet, especialmente o arquiteto, que faz ligações internacionais a trabalho e se projeta da casa para o mundo a partir de seu website e do programa de televisão. Além disso, ao ser uma "casa de grife", a Curutchet está sujeita aos olhares como se fosse uma obra de arte em uma exposição - é uma casa, mas é também um objeto arquitetônico notável, e pode ainda ser utilizada para jogos de sedução e de poder. Esse processo de comunhão com o público vem de mãos dadas com alguns preceitos da arquitetura modernista, como a utilização das falsas paredes de vidro e das largas janelas horizontais de Le Corbusier, que redefiniram o espaço privado e o abriram ao exterior - características que se destacam na Curutchet. Seu portão é o maior emblema disso, pois está como flutuando na fachada, e para ingressar ao local pode-se passar por ele ou não -e sua utilidade é uma simples convenção.

Assim, ainda que a virtualização do cotidiano diminua distâncias entre pessoas e lugares, e as transparências permitam o contato entre interior e exterior, apenas Leonardo pode se mover e mover o 
seu olhar, tanto dentro como fora da Curutchet - enfatizando o contraponto entre celeridade, multidirecionalidade e fluidez dos movimentos nos espaços virtuais versus obstrução e caráter travado dos movimentos no espaço físico, o que igualmente se relaciona com as fronteiras. Víctor não pode ocupar a casa nem que seja para defendê-la (ele morre nela), nem construir um novo espaço (a janela é fechada).

\section{Uma janela, dois mundos}

El hombre de al lado constata e desdobra um problema de comunicação e negociação na diferença que provoca uma mudança radical na forma de morar na Casa Curutchet: as vozes discordantes de Leonardo e Víctor passam o filme buscando meios de acomodação, e esses personagens são construídos a partir de suas oposições - e também de suas complementaridades. O enfrentamento dessas personalidades e de suas posições é bosquejado já na primeira sequência: o filme se inicia com a tela negra e os créditos, enquanto ouvimos o canto de passarinhos, sugerindo um lugar calmo e bucólico. Logo, a tela passa a ser dividida ao meio - de um lado, branca; de outro, cinza. Essa transição da tela negra à tela dividida é acompanhada pelo som da passagem de um carro em alta velocidade, que buzina, ressignificando nossas impressões sobre o local da ação. Ouvimos também um cachorro latir, o que reforça essa sensação, já que vai se instaurando uma sutil poluição sonora. Ao fim dos créditos, surge uma marreta que começa a quebrar a parte cinza da tela, que então descobrimos ser uma parede - e cada lado da tela é uma face da parede. Não vemos quem detém a marreta, apenas os golpes. Conforme a marreta avança em seu trabalho, o lado branco vai se rachando, até que se abre um buraco, através do qual os dois lados se conectam. Nesse momento, podemos notar que a parede cinza não era pintada dessa cor, mas era escura pela falta de luz no ambiente.

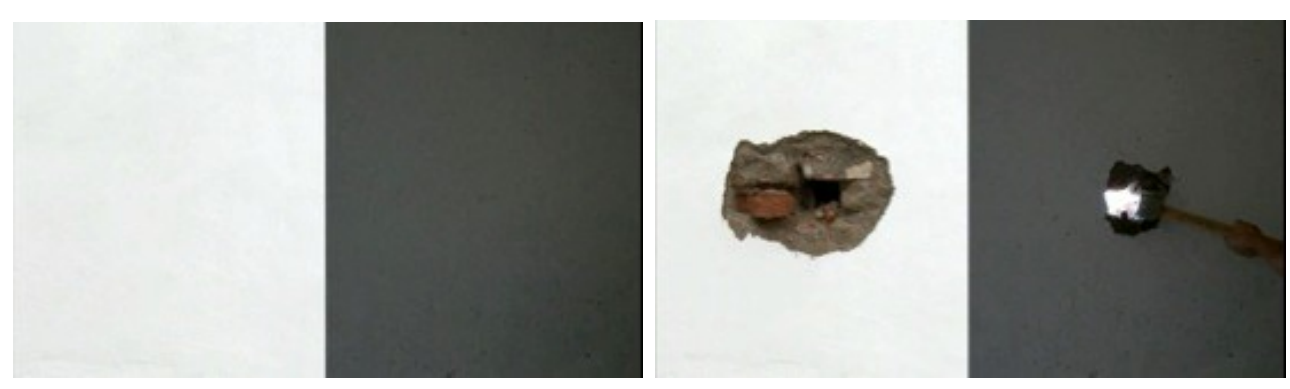

Imagens 3 e 4: El hombre de al lado (Gastón Duprat e Mariano Cohn, 2009) | (C) Aleph Media

Em seguida, conhecemos Leonardo: em um close up (que sugere a íntima relação que a câmera terá com esse personagem), o vemos acordar devido ao som das marretadas. Ele se levanta e continua sendo acompanhado de perto pela câmera que, assim, faz seu 
primeiro recorrido na casa pelas mãos de seu anfitrião, enquanto este busca a origem dos ruídos. A proliferação do branco nesse espaço nos leva a intuir que Leonardo está do lado "iluminado" da tela dividida. Após um breve passeio, ele verifica que estão abrindo um buraco na parede que dá para a janela de sua casa e grita agressivamente com o operário que faz o serviço.

Nessa primeira aparição, Leonardo nos é apresentado como autoritário e mal-educado, perfil reforçado por sua fala desdenhosa ao olhar para o buraco: "que país feo, la puta madre!" (transcrito diretamente do filme). Porém, logo depois, teremos outras informações sobre o personagem, enquanto ele cria um site pessoal: arquiteto e designer importante que ganhou prêmios internacionais, seus produtos são sucesso de venda no mundo todo (o site deve ter vários idiomas: espanhol, inglês, francês, italiano, alemão, japonês e chinês), é culto (enfatiza a importância do chinês em sintonia com as tendências contemporâneas) e conhece várias línguas (corrige a ortografia em outros idiomas e faz ligações internacionais). Quando a câmera deixa a tela do computador para mostrar a situação na qual Leonardo dá instruções ao webdesigner, vemos essa sofisticação na composição do ambiente, confirmação de sua genialidade profissional, que será enfatizada, durante todo o filme, através da alternância entre planos gerais e primeiros planos e da exibição dos cômodos da Curutchet a partir de variados ângulos, demarcando o protagonista e o espaço minimalista e ordenado da casa, frente a um exterior vegetal belo e tranquilo. Assim, Leonardo e a casa onde vive são emblemas do design, da excelência e do bom gosto.
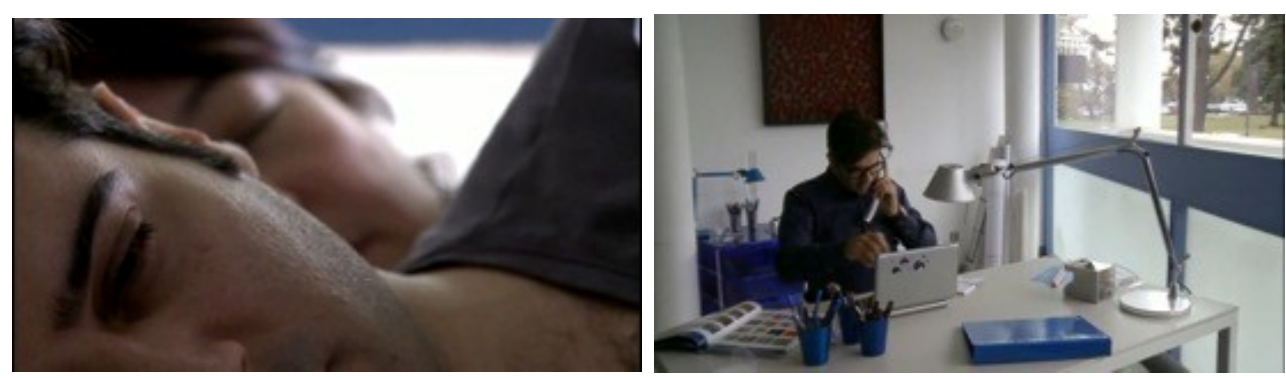

Imagens 5 e 6: El hombre de al lado (Gastón Duprat e Mariano Cohn, 2009) | ( ) Aleph Media

Entretanto, a arrogância e a crispação do arquiteto na primeira cena ecoarão em diversos momentos, contrariando e poluindo seu perfil virtuoso: ele repete com o tio de Víctor a postura ofensiva que havia tido com o pedreiro, interrompe sem motivo uma entrevista para a televisão, destrata seus alunos. Quando busca reconhecer alguma qualidade no outro, sempre o faz de maneira irônica, de modo a inferiorizá-lo, como ao considerar a saída com Víctor uma experiência antropológica. 
A vivência na Curutchet também vai apresentar desajustes, reforçando a hipótese de que Leonardo e sua casa funcionem como reflexos um do outro. Por um lado, dá-se uma deterioração das relações familiares: no começo do filme, Lola brinca nas rampas de entrada da casa e se deixa ser acariciada pelo pai, recepcionando-o em sua chegada; os biquitos [beijinhos] pedidos pela mulher são correspondidos, ainda que burocraticamente. Um pouco depois, há uma mudança drástica nesse clima: a pré-adolescente comporta-se com um alheamento muito mais profundo do que o esperado para essa idade, ignorando qualquer tentativa de contato. ${ }^{7}$ Já Ana transforma-se em uma personagem decididamente agressiva, embora sua violência se encene apenas no plano verbal. A todo o tempo, ela dá ordens ao marido (até o biquito é uma exigência) e o trata de pelotudo. ${ }^{8}$ Enfim, apesar de maltratar desconhecidos, humilhar seus alunos e forçar uma postura de superioridade, o arquiteto não consegue o mínimo respeito de sua filha e passa a ter uma relação conflituosa com a mulher - com quem mantém diálogos quase exclusivamente sobre o problema com o vizinho.
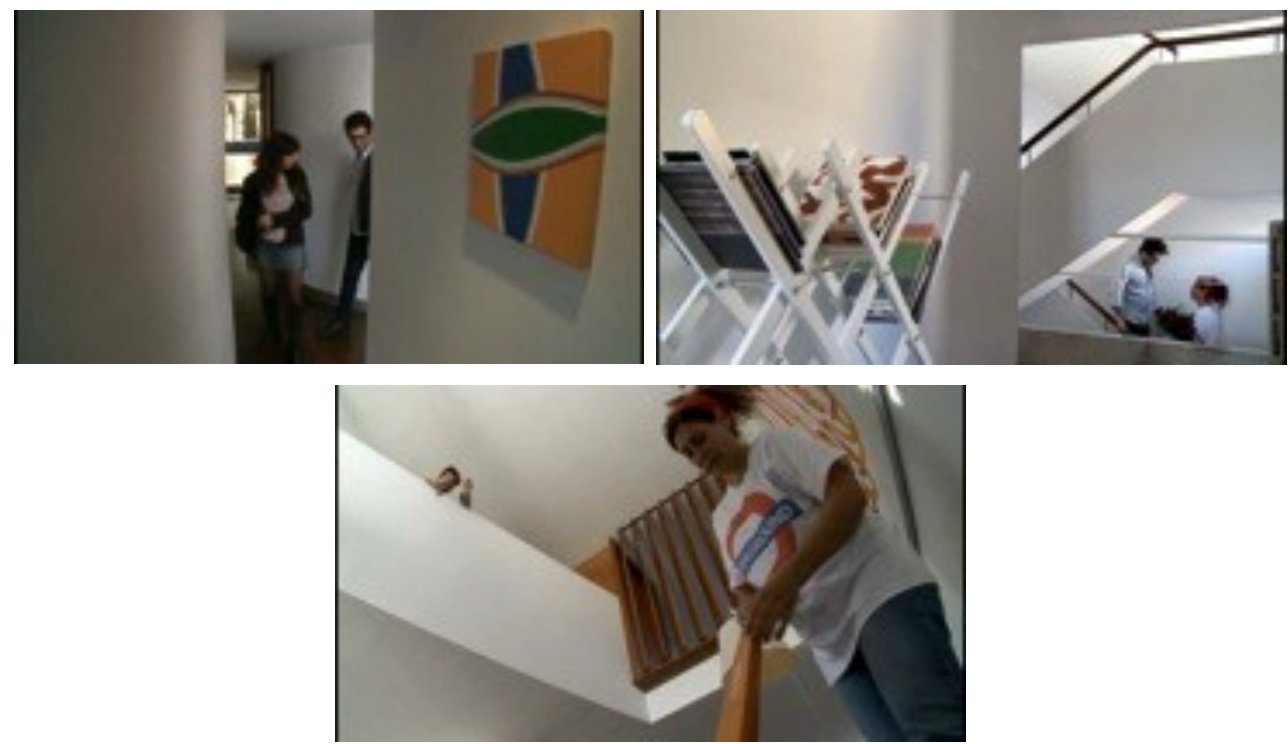

Imagens 7, 8 e 9: El hombre de al lado (Gastón Duprat e Mariano Cohn, 2009) (C) Aleph Media

Por outro lado, a casa parece obstaculizar a fluidez das relações entre seus moradores: devido às frequentes deambulações de Leonardo, ela é captada de modo fragmentado, e é impossível armar

\footnotetext{
${ }^{7}$ Na verdade, Leonardo é o único que tenta empreender uma comunicação com a garota dentro da casa, mas nunca o faz diretamente, pegando atalhos que podem justificar seu fracasso: ou propondo o diálogo pelo telefone, ou dando um sermão que nada diz, ou puxando assunto sobre as miniaturas cool que compraram no MoMA de Nova York (momento em que está vestido com um macacão, traje infantilizado que o faz parecer ainda mais desajeitado).

${ }^{8} \mathrm{O}$ termo pelotudo tem uma porção de significados e pode ser utilizado de diversas maneiras, em diversas ocasiões na Argentina. No Brasil, poderia ser idiota, babaca.
} 
um mapa mental do lugar que, como já foi comentado, acaba se configurando como um labirinto, o que justifica a dificuldade de um encontro e propicia os desencontros. Nenhuma tomada se conforma como um establishing shot ${ }^{9}$ que dê conta de organizar espacialmente o cenário.

Essa fragmentação vai se repetir na representação de Leonardo, com destaque para a cena em que ele tenta entabular um diálogo com a filha e aparece refletido, em pedaços, nos espelhinhos circulares da parede colorida do quarto. ${ }^{10}$ Enquanto cozinha, a cabeça de Leonardo é substituída pelo armário; enquanto trabalha, seu corpo é substituído pelo notebook. Além disso, Lola não se desconecta dos fones de ouvido; Ana sempre possui algo em suas mãos: o celular, o telefone, um livro (e seu corpo também é substituído pelo notebook em mais de uma ocasião). Como observa Frederico Canuto (2012), Leonardo e sua família são sempre vistos a partir de seu entorno: enquadrados pelas janelas e portas, rodeados de objetos, a câmera se esforça por mostrá-los ao mesmo tempo que mostra o ambiente em que vivem. Há uma relação simbiótica entre os espaços/objetos e os habitantes da Curutchet, e os corpos são como extensões da casa.
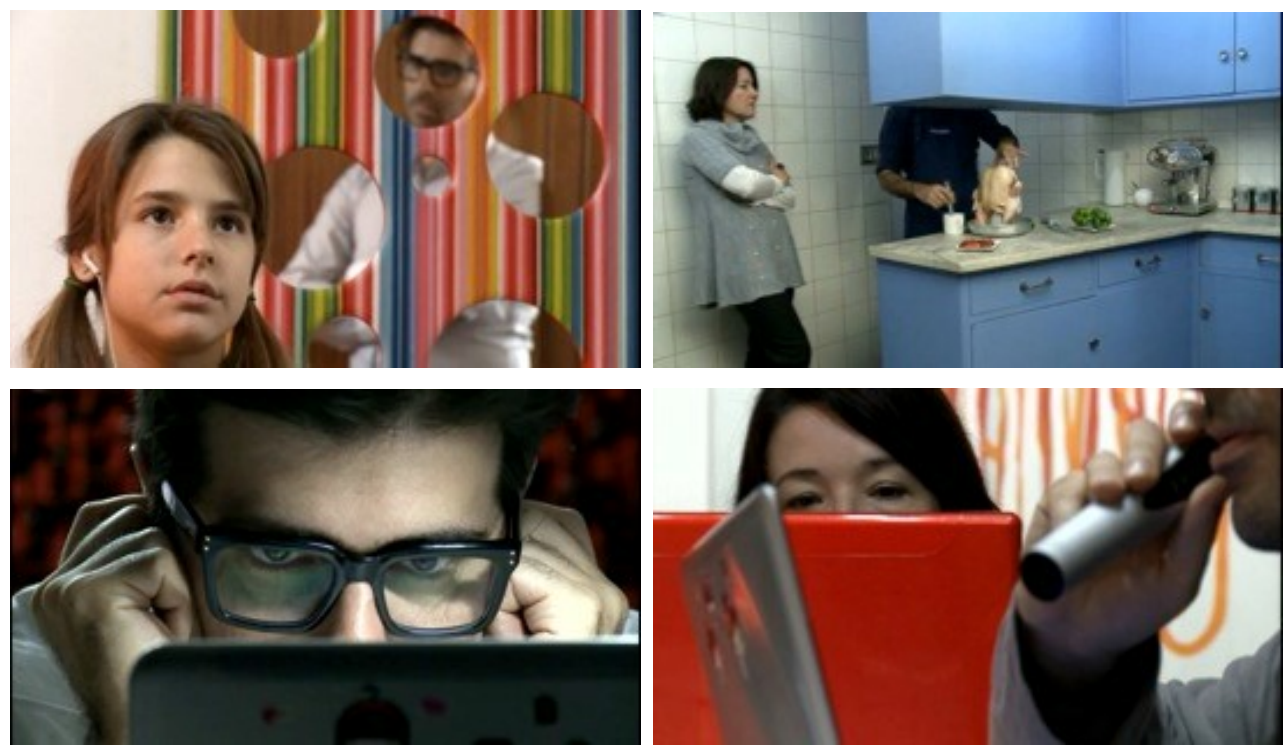

Imagens 10, 11, 12 e 13: El hombre de al lado (Gastón Duprat e Mariano Cohn, 2009) (C) Aleph Media

Esses objetos, na maioria das vezes, não são congregadores ao contrário, aparatos como o notebook ou o fone de ouvido

\footnotetext{
${ }^{9}$ As tomadas de orientação ou estabelecimento (establishing shots) brindam ao espectador uma noção do lugar onde se localiza a ação e estabelece relações espaciais entre os personagens e tudo o que há entre eles.

${ }^{10}$ Como na cena em que veste o macacão, a imagem de Leonardo se reveste de um ar meio engraçado, meio patético, nutrindo a impotência que este encarna frente à filha, destoante da persona poderosa que demonstra o tempo todo.
} 
individualizam os espaços. Entre o despedaçamento da casa promovido pela mise en scène e a profusão de elementos individualizantes, os moradores terminam encerrando-se em seus cômodos, ao invés de socializarem nas áreas de convivência pensadas pelo arquiteto franco-suíço, e ocupando os espaços comuns apenas quando há visitas. Do mesmo modo, apesar de ter sido construída privilegiando a entrada de luz, a residência aparece como se estivesse sempre na penumbra (outra correspondência entre a casa e - o lado sombrio de - Leonardo?); e, ainda que Le Corbusier buscasse que suas construções estivessem ligadas à cidade, os personagens que habitam a Curutchet insistem em se separar do espaço público - ao sair da casa, entram diretamente dentro do carro, e a interação com o exterior é permitida apenas se fundada em um olhar de admiração.

Assim, valores associados aos projetos de Le Corbusier estão suspensos na diegese, o que se repete no papel assumido pela janela no desenvolvimento da trama. Como verifica Carolina Soria (2010), a janela é elemento central e constitutivo da disputa de Leonardo e Víctor: é o eixo condutor de todas as ações, intervém no devir dos personagens e modifica os vínculos que estabelecem entre si. O filme começa com a abertura da janela e termina com seu fechamento. A comunicação entre interior e exterior, e o encontro de dois mundos antes separados pela parede, se dá através da janela. Ela estabelece uma aproximação ao romper a medianeira: vizinhos que nunca se viram começam a se frequentar por causa da janela. A parede fazia com que Leonardo não precisasse de participar de outra vida que não fosse a sua própria, e a janela é uma reconfiguração social que coloca os limites à prova durante todo o longa-metragem.

Recupera-se, em um sentido inverso, a concepção arquitetônica da janela de Le Corbusier, na qual os muros exteriores se liberam e as janelas abarcam a largura da construção, melhorando a relação com o exterior. Aqui, a janela permite o ingresso do mundo exterior na vida da família Kachanovsky, colocando-a em crise, representando a abertura, a visão e a comunicação com um exterior que os personagens constantemente negam e querem ocultar, e que fica formalmente fora de campo. (Soria 2010, 2)

Essa constante ressignificação de alguns preceitos que guiaram a construção da Curutchet pode ser mais bem compreendida quando retomamos a tela partida que abre $O$ homem ao lado. Para além do dualismo conceitual - branco/cinza, luz/escuridão, refinado/rústico - que essa imagem sugere e que paira sobre toda a narrativa (sendo, também, ressignificado no final), há uma proposta que advém da videoinstalação Boquete, ${ }^{11}$ de Gaspar Libedinsky, na qual a sequência se inspira (segundo informam os créditos do filme). Boquete faz parte da série Productos caseros, sobre a transformação

\footnotetext{
${ }^{11}$ Disponível em https://www.youtube.com/watch?v=Db-IITg60ls.
} 
da penitenciária de Caseros $^{12}$ por parte dos próprios presos que, durante um motim em 1984, abriram boquetes (pequenos buracos) nas paredes do edifício para circular entre andares e para se comunicar com os parentes que apareciam nas calçadas.

Como analisa Marina Moguillansky (2014), os boquetes rompiam com o propósito arquitetônico do edifício e, através deles, os presos reverteram, ao menos parcialmente, a lógica dos panóticos ${ }^{13}$ que norteia as prisões. De acordo com a autora, Libedinsky reflete sobre o reverso da costumeira afirmação de que a arquitetura condiciona a experiência dos sujeitos, preferindo pensar sobre as formas em que a ação humana transforma a arquitetura - aspecto nutrido todo o tempo por Cohn e Duprat através dessas ressignificações.

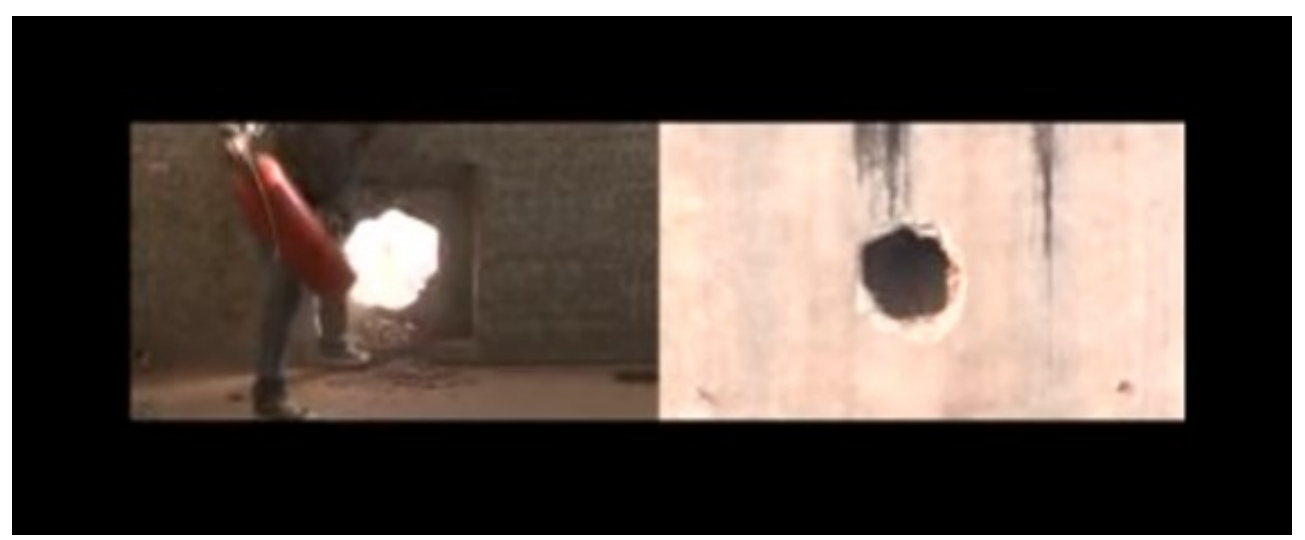

Imagem 14: Boquete, parte da série Productos Caseros (Gaspar Libedinsky, 2007) (C) Gaspar Libedinsky.

Nesse sentido, vai emergindo - da Curutchet e de Leonardo o efeito daquilo que Sigmund Freud conceituou como estranho. No começo de seu escrito sobre o tema (1919), o autor apontou o estranho como aquilo que é assustador, que provoca medo e horror, e que está ligado ao que é desconhecido. Porém, a partir do estudo de casos e, especialmente, da investigação sobre a etimologia da palavra, Freud qualifica o estranho como aquela categoria do assustador que remete para o que é conhecido e, há muito, familiar. Entre os

\footnotetext{
${ }^{12}$ A penitenciária de Caseros, na cidade de Buenos Aires, foi uma penitenciária em modelo panótico idealizada em 1960 e cuja construção foi abandonada após informes que alegavam a inumanidade e inviabilidade do projeto. A obra foi retomada em 1969, durante o governo ditatorial de Juan Carlos Onganía, e inaugurada dez anos depois sob outro governo ditatorial, de Jorge Rafael Videla. Em 1984, uma violenta rebelião abalou as estruturas do edifício, fazendo com que se iniciasse um processo de desativação da prisão, concluído em 2000.

${ }^{13}$ Modelo de prisão ou de torre de observação idealizado para que os vigilantes possam facilmente ver todas as partes de um edifício ou de um recinto, sem serem vistos. O efeito mais importante do panótico é induzir no prisioneiro um estado consciente de permanente de visibilidade que garante o funcionamento automático do poder.
} 
diferentes matizes de significado que a palavra heimlich (em inglês homely - familiar) exibe, descobre-se um que é idêntico ao seu oposto, unheimlich (unhomely - estranho).

Assim, o que é heimlich vem a ser unheimlich. Em geral, somos lembrados de que a palavra heimlich não deixa de ser ambígua, mas pertence a dois conjuntos de ideias que, sem serem contraditórias, ainda assim são muito diferentes: por um lado significa o que é familiar e agradável e, por outro, o que está oculto e se mantém fora da vista. Unheimlich é habitualmente usado, conforme aprendemos, apenas como o contrário do primeiro significado de heimlich, e não do segundo. Sanders nada nos diz acerca de uma possível conexão genética entre esses dois significados de heimlich. Por outro lado, percebemos que Schelling diz algo que dá um novo esclarecimento ao conceito do unheimlich, para o qual certamente não estávamos preparados. Segundo Schelling, unheimlich é tudo o que deveria ter permanecido secreto e oculto, mas veio à luz. (...) Dessa forma, heimlich é uma palavra cujo significado se desenvolve na direção da ambivalência, até que finalmente coincide com o seu oposto, unheimlich. Unheimlich é, de um modo ou de outro, uma subespécie de heimlich. (Freud 1976) ${ }^{14}$

\section{O homem e o medo - do lado de dentro}

A casa (e nada mais familiar que o lar) de $O$ homem ao lado vai se descortinando como um lugar escuro, sinuoso, barulhento e desprotegido - estranhezas que assomam no comportamento de Leonardo e convergem em sua atitude final. E o "susto" do espectador é sublinhado pelo fato de o arquiteto ser nosso personagem familiar: durante todo o filme, seguimos Leonardo. Conhecemos sua residência, sua família, seus negócios, seu cotidiano, até um pouco de sua intimidade. Na maior parte do tempo, a câmera está posicionada sobre seu ombro, mostrando-nos o que ele vê; ou o capta de perto, fazendo com que nos conectemos a ele e a seus sentimentos revelados por suas expressões.

Por outro lado, há poucos elementos que exponham um contexto que possa explicar algo sobre Víctor; não encontramos pontos de sua biografia para retornar nem presenciamos seu dia a dia. Ele é enquadrado sempre frontalmente, e sua poker face ${ }^{15}$ ocupa todo o plano, sem sobras de espaço, ou é focada e destacada de um fundo disforme. Nunca entramos em sua casa (nem com Leonardo), apenas temos acesso a seu furgão em uma tomada fixa (ao contrário da

\footnotetext{
${ }^{14}$ A página não é indicada, pois utilizei um arquivo digital (proveniente da edição publicada pela Imago em 1976) que não contava com numeração.

${ }^{15}$ Expressão impassível, vazia, não demonstrando nenhuma emoção.
} 
câmera que passeia por toda a casa do arquiteto).${ }^{16} \mathrm{O}$ que nos é dado de Víctor é a existência de um tio, a maneira que se veste, seu gosto pela caça, sua arte feita a partir de munição velha, mas, especialmente, sua imagem captada em primeiro plano. A maneira de apresentá-lo mantém o personagem enigmático (traço necessário para conservar a tensão da narrativa): ele é, praticamente, um desconhecido.

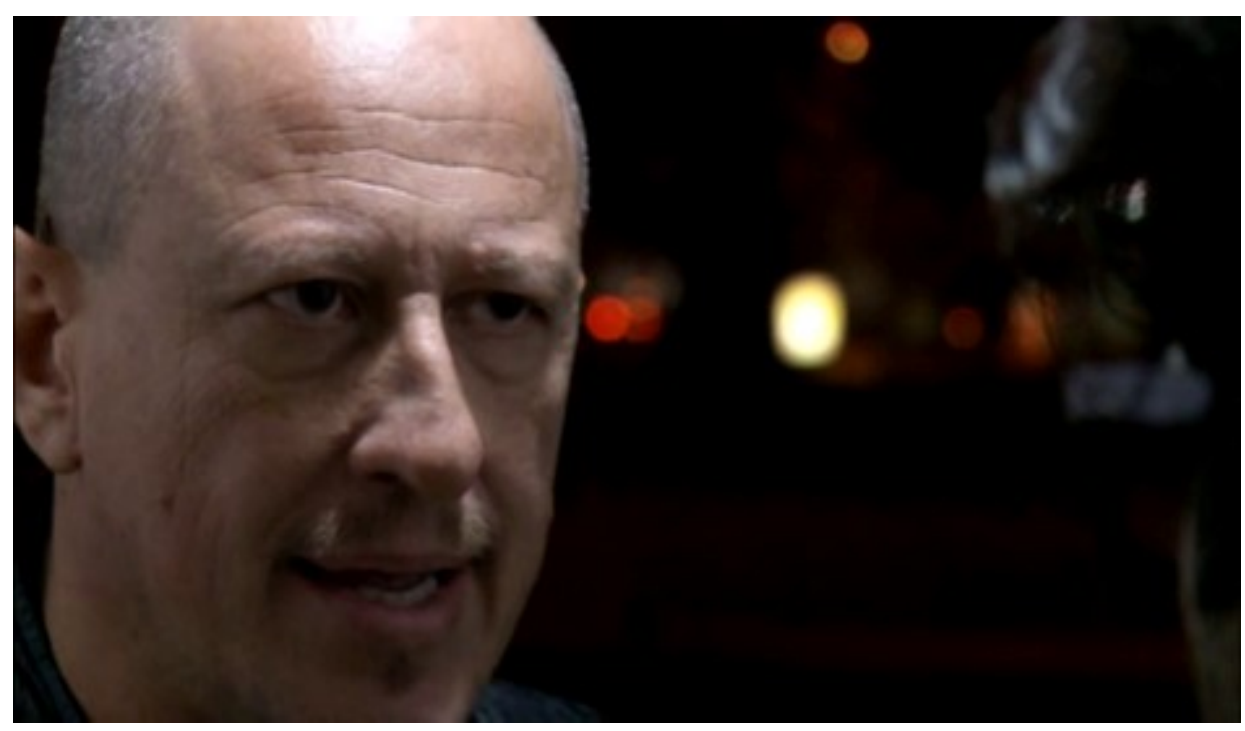

Imagem15: El hombre de al lado (Gastón Duprat e Mariano Cohn, 2009) | (c) Aleph Media

Assim, apesar das intervenções desestabilizadoras de Víctor, que ativam os quiproquós da trama, acompanharemos o desenvolvimento das situações através de Leonardo. A história se estrutura a partir dos diálogos travados entre os dois, mas nunca há uma situação de campo e contracampo, sendo que sempre ocupamos o lugar do arquiteto. Além do ponto de vista desse personagem, estamos sob seu ponto de escuta - procedimento significativo, já que Víctor e tudo o que ele traz desse "mundo misterioso" chegam, especialmente, na forma de ruídos.

É importante considerar, então, que vemos Víctor pela perspectiva de Leonardo, que o percebe e faz com que o percebamos como um mal-educado, invasivo, preconceituoso, machista, um rústico atrás do qual - segundo os critérios de cada um, e aqui sob os

\footnotetext{
${ }^{16}$ Nesse único acesso que temos ao universo de Víctor, tudo entra em conflito com o padrão estético clean e racional do mundo dos Kachanovsky, com uma profusão de clichês do brega: acarpetado de oncinha, bola de espelhos como as que ficam nos tetos de nightclubs e excessos em geral - de cores, de objetos, de materiais. É evidente o desconforto de Leonardo, que não tem jeito para manejar nada (quando logra sustentar a cuia de mate, se queima).
} 
critérios de Leonardo - se aloja um violento perigoso. ${ }^{17}$ A postura pedante de Leonardo tende a suscitar antipatias que nunca se revertem em simpatia a Víctor, que paira todo o tempo em um limbo entre o ridículo e o ameaçador, fazendo-nos rir, mas sem aderir totalmente a ele. $\mathrm{O}$ filme alterna nossa inclinação entre um e outro personagem, mas nunca desafia efetivamente a nossa impressão de qual deles é digno de desconfiança.

Essa forma de localizar os personagens, articulada à suspeita que rege a relação que o protagonista estabelece com Víctor, me levou a pensar em El hombre de al lado como uma possível versão remixada do conto "Casa tomada”, de Julio Cortázar. Publicado pela primeira vez em uma antologia organizada por Jorge Luis Borges (1946) e, posteriormente, incluído no livro Bestiario (1951), o conto suscitou uma infinidade de interpretações, sendo a ideia da casa tomada um dos mais importantes eixos conceituais para se pensar o país desde então.

O conto narra a história de um casal de irmãos que vivem, sozinhos, em um velho casarão familiar, e que têm de ir cedendo quartos e espaços do mesmo a um invasor que produz tanto temor que não pode ser enfrentado, apesar de não se saber exatamente do que ou de quem se trata. Só resta aos irmãos retroceder e fechar a última porta que os separa do invasor, que pouco a pouco se apropria de mais cômodos e ganha terreno até que a dupla abandone a casa. Para Juan José Sebreli - cuja leitura de "Casa tomada" se converteu em um lugar comum da crítica, muitas vezes sobrepondo-se ao conto em si (Piglia, 1993) -, o texto expressa uma angustiosa sensação de invasão que o cabecita negra provocava nas classes média e alta no período do primeiro peronismo (1946-1952). Cabecita negra é um termo utilizado na Argentina para denominar, pejorativamente, um setor da população associado às pessoas de cabelo escuro e pele mo-

\footnotetext{
${ }^{17}$ Por exemplo, ele não é percebido dessa forma por Elba (que o considera um vizinho) nem por Lola, a quem a janela parece agradar pela possibilidade de se divertir com o misterioso teatrinho entre naïf e perverso que Víctor encena para ela - feito com alimentos baratos nos quais se lambuza e contamina, oposto à assepsia que prevalece na vivência da garota. Não há nada em comum entre esses indivíduos que não sejam as botinhas que se mexem nos dedos de Víctor - iguais (as mesmas?) às da boneca de Lola - e o fato de estarem ali, disponíveis para conhecer o desconhecido.
} 
rena pertencentes à classe trabalhadora. ${ }^{18} \mathrm{O}$ conto seria, então, uma metáfora da Argentina tradicional que retrocedia sob o avanço do peronismo e da participação na vida pública dos setores populares, até então marginalizados. Outras análises dispensam a questão política e se baseiam em elementos psicanalíticos (a casa é um útero do qual os irmãos são expulsos), ou se centram na possível relação incestuosa dos personagens (desde o desejo recalcado que vai irrompendo entre eles até a comparação com a história de Adão e Eva banidos do paraíso). A presença de fantasmas, antepassados que atormentam os irmãos, é outra interpretação recorrente.

Aqui, me parece produtivo pensar como todas essas possibilidades - tanto em "Casa tomada" como em $O$ homem ao lado - coincidem em suas estreitas relações com o medo, e como este medo pode se deslocar do desconhecido para o familiar.

De saída, instala-se uma cumplicidade do espectador com Leonardo, que é movido pelo medo que sente do homem ao lado suas atitudes são impulsionadas pela necessidade de se proteger e se distanciar, evitar e até eliminar aquilo que causa medo. Víctor é a alteridade potencialmente perigosa da qual se deseja manter afastado - mas que pode ser observada com prudente curiosidade, como no método antropológico, nos dizeres do próprio Leonardo (Savoini, Triquell 2013).

O medo nasce com o descompasso dos códigos culturais dos personagens: em primeiro lugar, o arquiteto depara-se com a inutilidade da lei para resolver o conflito. De acordo com Anderson Roberti dos Reis, "a altercação e as dificuldades na solução do problema surgem de uma diferença fundamental no modo como cada um dos personagens compreende e se relaciona com a noção de norma" (2012, 245). ${ }^{19}$ Para Leonardo, a questão legal é suficiente

\footnotetext{
${ }^{18}$ O termo teve origem na cidade de Buenos Aires, durante os anos 1940, quando se iniciou uma grande migração interna - especialmente das zonas rurais e das províncias do norte - em direção à capital e a outros grandes centros urbanos para o trabalho na incipiente indústria nacional (cujo rápido processo de implantação havia se iniciado em meados da década anterior). Este contingente inundou as margens das cidades (somando-se aos imigrantes europeus pobres) e modificou completamente suas composições sociais. Ao se congregarem, majoritariamente, sob o estandarte peronista, adquiriram um rápido e inusitado poder político. As classes média e alta se sentiram ameaçadas ante a presença da crescente massa operária que "invadia" os espaços - urbanos - que eles haviam considerados como seus. É nesse contexto que batizaram seus "inimigos" como cabecitas negras, unificando sob esse apelido depreciativo sujeitos que compartiam não apenas traços físicos, mas também um lugar de procedência, uma consciência de classe e uma filiação política (Cremona 2013).

${ }^{19}$ Ademais, os personagens compreendem e se relacionam com o significado da janela (daquela janela) de maneiras diferentes: para Leonardo, a janela não serve para nada e é puramente uma invasão de privacidade; para Víctor, a janela serve para receber uns raios de sol, para os vizinhos conversarem, para provarem receitas um do outro, para fazer um teatrinho e até para averiguar se a casa contígua está em segurança.
} 
para justificar a não construção da janela e ele não entende a resistência de Víctor. Segundo o protagonista, as leis são imperativas e universais (como afirma, aquela obra não seria aceitável "nem no Japão, nem na China, nem na puta que o pariu" [transcrito diretamente do filme]) e por isso devem ser respeitadas, independentemente das circunstâncias.

Ser legalista é a única possibilidade para Leonardo, enquanto para Víctor é uma possibilidade entre outras - com o que concorda um amigo do arquiteto: "a lei diz uma coisa, mas a vida diz outra"; "essas coisas se ajeitam falando" (transcrito diretamente do filme). Para Víctor, a manutenção da ordem está mais ligada a mecanismos da moral e da consciência individual do que a regramentos jurídicos, e ele se apoia nessas condições. Ao manejar um código amistoso, propondo um tête à tête amigável e hospitaleiro, Víctor desconstrói os argumentos de Leonardo, ao mesmo tempo que os reveste de um matiz autoritário, enfraquecendo a "superioridade" da instância legal.

O mesmo se dá quando o arquiteto, com o objetivo de "assustar" Víctor, envolve na contenda um advogado que sugere deixar o homem esperando para indicar a existência de uma assimetria de posições - atitude à qual Víctor responde de maneira física (o que ele descreve como "um puxão de orelha"), anulando a vantagem que Leonardo esperava ganhar. Ao se encontrar com Víctor, Leonardo se encontra com outro universo, no qual suas armas discursivas, seu poder e todas as suas seguranças são neutralizadas - impotência que aprofunda seu temor.

O modo como a relação entre os personagens se desenvolve faz do título do filme uma escolha evidente: o homem frisa distância, pois se trata de um desconhecido, a despeito da proximidade espacial (ao lado). Leonardo nunca chama Víctor por seu nome, tampouco o trata como vizinho (o que os ligaria de alguma forma), e se refere a ele apenas como "o homem ao lado", "selvagem", e outros termos depreciativos, que servem para marcar uma separação entre eles - não apenas física, mas um afastamento que os impeça de se relacionar.

Cada descompasso entre Leonardo e Víctor empurra o último a assumir o papel de monstro - o que se entrosa com sua voz grave e gutural, com seu emergir de um buraco negro, com suas aparições inesperadas e desagradáveis, com o som de pancadas secas e furadeiras agudas a pressagiar a moléstia que causará e a partir da qual o arquiteto se vê forçado a redefinir sua rotina, da mesma maneira que os irmãos de "Casa tomada" redefiniram as suas, ao ouvirem ruídos imprecisos. Entretanto, ao passo que os irmãos recuam até se retirarem completamente, Leonardo não chega a ter sua casa tomada. Nesse sentido, o que sucede a Leonardo se parece mais com o que sucede a outro personagem da literatura argentina: o Sr. Lanari, do conto "Cabecita negra", de Germán Rozenmacher, publicado em 
1962 - segundo Piglia (1993), uma resposta ao comentário de Sebreli sobre "Casa tomada".

"Cabecita negra" aborda as relações racistas e classistas que se desenvolveram no país, depois de 1940, através do encontro do Sr. Lanari, um próspero comerciante que, ao sair do aconchego de seu lar em uma noite de insônia, se depara com uma dupla de - segundo ele - cabecitas negras que acabam ingressando em sua casa, "seu refúgio, onde era o dono, onde podia viver em paz, onde tudo estava em seu lugar, onde o respeitavam" (Rozenmacher 1971, 33) e que se converte no espaço dos outros, do escândalo, onde Lanari fica "aprisionado por esses negros" (Rozenmacher 1971, 36). Essa experiência de se sentir invadido é relatada pelo narrador onisciente como se fosse um pesadelo, a partir do qual Lanari reconhece a certeza de jamais estar seguro de nada.

Leonardo também é acometido por essa insegurança com a aparição de Víctor, a qual busca sanar, pedindo para Elba averiguar as fechaduras, consultando um especialista na proteção de residências e instalando um botão de pânico. Porém, enquanto a "invasão" sofrida pelo Sr. Lanari se dá de forma literal (com os corpos adentrando o recinto), o ingresso de Víctor na Curutchet (que dança, ocupando toda a sala e todas as atenções; que desfruta de todos os movimentos da cadeira star de Leonardo) é apenas a cereja do bolo de uma incursão que se inicia com seu olhar - e é nesse ponto que os objetos do medo começam a se embaralhar.

\section{Palavras finais}

Os Kachanovsky já são observados, mas em uma posição exibicionista e confortável. Morar em um marco da arquitetura modernista reforça o sucesso de Leonardo; há sempre turistas tirando fotos do local e alunos de arquitetura têm aulas em sua calçada. Ele não se incomoda com esse olhar admirador, e o toma como sendo também para si. Em primeiro lugar, como analisa Vera Lúcia Follain Figueiredo,

A luta pelo direito à janela, travada por Víctor, recoloca (...) a questão da visibilidade, isto é, não se trata somente de quem tem o direito de ter acesso a um raio de sol, mas também de quem tem o direito de ver e ser visto. O olhar de admiração dos turistas, legitimado pela capacidade de reconhecer o valor artístico da obra do arquiteto, não incomoda Leonardo: o que o desespera é o olhar do vizinho, do homem comum que não possui a competência cultural específica para render homenagem àquele monumento arquitetônico, e, portanto, não sabe respeitar a distância que sua sacralização exigiria. (Figueiredo 2012, 111)

Em segundo lugar, o filme também trabalha com o contraponto entre a janela não controlada, que "expõe" o sujeito naquilo que ele não quer oferecer ao olhar do outro, e as janelas controladas que colocam 
em circulação "imagens de si": além da casa-vitrine, o website de divulgação do arquiteto, as filmagens feitas pelo avô dos lindos e felizes membros da família - que escondem uma crise criativa e relações familiares problemáticas.
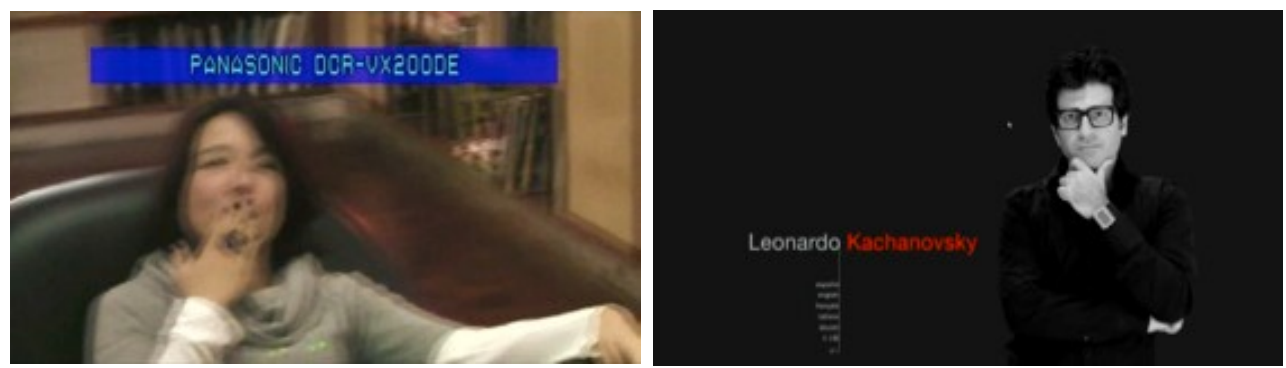

Imagens 16 e 17: El hombre de al lado (Gastón Duprat e Mariano Cohn, 2009)

(C) Aleph Media

Em terceiro lugar, a "invasão" e o "imiscuir-se" do outro que se teme são apresentados como uma projeção da própria curiosidade e bisbilhotice. Vemos muito mais Leonardo e Ana espionando Víctor do que o contrário (embora muitas das falas de Víctor autorizem a conjecturar que ele também espiona). Mais uma vez, o que provoca a fissura que desestabiliza a casa é repensado e localiza o estranho no que é familiar.

O desfecho do filme não deixa dúvidas sobre esse deslocamento de posições que vinha se anunciando: o contraste entre o chá de cadeira do advogado e o puxão de orelha, entre a violência "civilizada" (oblíqua) de Leonardo e a violência "bárbara" (mais franca e direta) de Víctor, permanece até o fim, com Víctor utilizando uma escopeta para proteger Lola e Elba e Leonardo deixando de pedir socorro médico para o vizinho que agoniza. Como afirma Gabriela Copertari (2012), o filme cria um lugar de identificação para o espectador, que termina se revelando como profundamente incômodo. É um lugar a partir do qual se projetam as fantasias e os preconceitos com relação à ameaça do outro e que se apresenta não apenas como equivocado, mas monstruoso, pois encarna a monstruosidade e a ameaça que o outro encarnava.
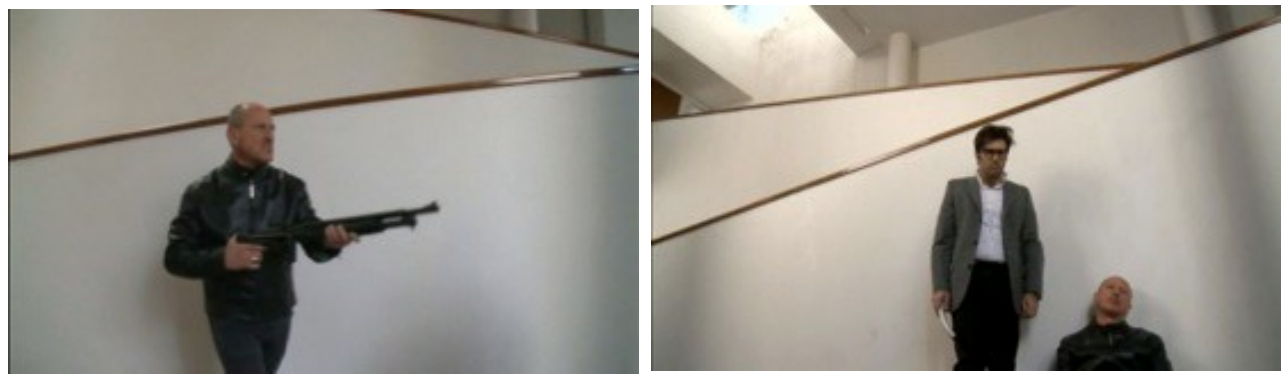

Imagens 18 e 19: El hombre de al lado (Gastón Duprat e Mariano Cohn, 2009) (C) Aleph Media 


\section{BIBLIOGRAFIA}

Barrenha, Natalia Christofoletti. 2015. "(Des)encontros na cidade em El hombre de al lado (Gastón Duprat e Mariano Cohn, 2009)”. Actas IV Congreso de la Asociación Argentina de Estudios de Cine y Audiovisual, editado por Laura Lorena Utrera. Buenos Aires: Asociación Argentina de Estudios de Cine y Audiovisual (AsAECA): 352-357. Acessado em 27 setembro 2017. http://asaeca.org/?wpdmdl=557.

Bauman, Zygmunt. 2008. Medo líquido. Rio de Janeiro: Zahar. . 2009. Confiança e medo na cidade. Rio de Janeiro: Zahar.

Bru, Josepa e Joan Vicente. 2005. “¿Qué produce miedo en la ciudad?". In La ciudad y el miedo, editado por Obdúlia Gutiérrez. Atas do VII Coloquio de Geografía Urbana, organizado pelo Grupo de Geografía Urbana de la Asociación de Geógrafos Españoles e pela Càtedra de Geografia i Pensament Territorial de la Universitat de Girona: 15-28. Girona: Universitat de Girona Publicacions.

Canuto, Frederico. 2012. "O homem armário". Revista Drops 12 (053.07), portal Vitruvius: fevereiro. Acessado em 17 março 2013.

http://www.vitruvius.com.br/revistas/read/drops/12.053/4 228.

Colomina, Beatriz. 1998. "The exhibicionist house". In At the end of the century. One hundred years of architecture, editado por Russell Ferguson. Catálogo da exposição homônima organizada por Richard Koshaleck e Elizabeth A. T. Smith em The Museum of Contemporary Art of Los Angeles: 126-165. Nova York e Los Angeles: Harry N. Abrams Publishers e The Museum of Contemporary Art.

Copertari, Gabriela. 2012. "Vistas del vecino en El hombre de al lado". Revista Canadiense de Estudios Hispánicos 37 (01), Cruzando fronteras e identidades en los cines hispánicos, outono: 157172. Acessado em 15 maio 2016. http://www.jstor.org/stable/24388785.

Cortázar, Julio. 1951. "Casa tomada”. In Bestiario, de Julio Cortázar. Buenos Aires: Sudamericana.

Cremona, Ana Carina. "Tres miradas sobre el racismo argentino: Cabecita negra de Germán Rozenmacher, Reinas de Juan José Hernández y La fiesta ajena de Liliana Heker". In Actas del Cuarto Congreso Internacional CELEHIS de Literatura 2011: áreas de literatura española, argentina e hispano americana, editado por Nicolás Abadie et. al com colaboração de María Pía Paseti e compilação de Aymará De Llano. Mar del Plata: 
Universidad Nacional de Mar del Plata. Acessado em 17 maio 2016.

http://www.mdp.edu.ar/humanidades/letras/celehis/congre so/2011/actas/ponencias/cremona.htm.

Delumeau, Jean. 2007. "Medos de ontem e de hoje". In Ensaios sobre $o$ medo, editado por Adauto Novaes. São Paulo: Editora Senac SP e Edições Sesc SP.

Eckert, Cornelia e Ana Luiza Carvalho da Rocha. 2008. "Cidade sitiada, o medo como intriga". Iluminuras. Revista eletrônica do banco de imagens e efeitos visuais 09 (21): 01-29. Acessado em 18 setembro 2015. http://seer.ufrgs.br/iluminuras/article/viewFile/9303/5374.

Gamberini, Marcela. 2012. "Una nueva cartografía para el cine argentino". Con los ojos abiertos, 04 junho. Acessado em 16 julho 2012.

http://www.conlosojosabiertos.com/una-nueva-cartografiapara-el-cine-argentino/.

Figueiredo, Vera Lúcia Follain. 2012. “A partilha do espaço urbano e a questão do outro próximo: repercussões no discurso teórico e na ficção cinematográfica”. Galáxia 12 (24), dezembro: 103114. Acessado em 30 abril 2016.

http://revistas.pucsp.br/index.php/galaxia/article/view/104 $13 / 9429$.

França, Andréa. 2003. Terras e fronteiras no cinema político contemporâneo. Rio de Janeiro: 7Letras.

Freud, Sigmund. 1976. "O estranho". In Obras completas, de Sigmund Freud, Volume XVII. Rio de Janeiro: Imago.

Hortiguera, Hugo. 2013. "Pensar las ciudades: espacios intermediales/espacios interdictorios como escenarios ficcionales en $\mathrm{El}$ hombre de al lado (de Mariano Cohn y Gastón Duprat) y Medianeras (de Gustavo Taretto)”. CiberLetras. Revista de Crítica Literaria y de Cultura 31, dezembro. Acessado em 02 maio 2016.

http://www.lehman.cuny.edu/ciberletras/v31/hortiguera.ht m.

2014. "Confianza, comunidad y eclipse del otro: una lectura de La vieja de atrás (2010) de Pablo José Meza y Un cuento chino (2011) de Sebastián Borensztein". Letras Hispanas: Revista de Literatura y Cultura 10 (02), outono: 35-50. Acessado em 02 maio 2016. http://gatodocs.its.txstate.edu/jcr:597632d5-8a13-4bf6-be72c0e5ade6af8a/10.2Hortiguera.

-_-. 2015. "Vecinos en disenso/espacios en disputa: cuestionamientos a un nuevo espacio social (urbano) en $\mathrm{El}$ hombre de al lado y en La última frontera de Mariano Cohn y 
Gastón Duprat”. Journal of Iberian and Latin American Research 21 (03): 345-359. Acessado em 02 maio 2016. doi:10.1080/13260219.2015.1153033.

Kehl, Maria Rita. 2007. "Elogio do medo". In Ensaios sobre o medo, editado por Adauto Novaes. São Paulo: Editora Senac SP e Edições Sesc SP.

Kessler, Gabriel. 2014. "O sentimento de insegurança e o medo na Argentina”. In A cidade e o medo, editado por Lia Zanotta Machado, Antonádia Monteiro Borges e Cristina Patriota de Moura. Brasília: Verbena/Francis.

Moguillansky, Marina. 2014. "Metáforas visuales de la desigualdad social en el cine contemporáneo argentino". In Actas IV Congreso de la Asociación Argentina de Estudios de Cine y Audiovisual, editado por Laura Lorena Utrera. Buenos Aires: Asociación Argentina de Estudios de Cine y Audiovisual (AsAECA): 848-854. Acessado em 04 maio 2016. http://www.asaeca.org/aactas/moguillansky.pdf.

Novaes, Adauto. 2007. "Políticas do medo". In Ensaios sobre o medo, editado por Adauto Novaes. São Paulo: Editora Senac SP e Edições Sesc SP.

Pastana, Débora Regina. 2003. Cultura do medo. Reflexões sobre violência criminal, controle social e cidadania no Brasil. São Paulo: Editora Método e Instituto Brasileiro de Ciências Criminais (IBCCRIM).

Piglia, Ricardo. 1993. La Argentina en pedazos. Buenos Aires: Ediciones de la Urraca.

Reis, Anderson Roberti dos. 2012. "A América negociada e os homens ao lado". Territórios e Fronteiras 05 (02), julho/dezembro: 243-260. Acessado em 17 março 2013. doi: $10.22228 /$ rt-f.v5i2.169.

Rozenmacher, Germán. 1971. "Cabecita negra”. In Cuentos completos, de Germán Rozenmacher. Buenos Aires: Centro Editor de América Latina.

Savoini, Sandra e Triquell, Ximena. 2013. “¿Miradas de qué clase? Construcciones cinematográficas de los conflictos de clase". Imagofagia 07, abril: 01-19. Acessado em 10 maio 2016. http://www.asaeca.org/imagofagia/index.php/imagofagia/ar ticle/view/351/303.

Soria, Carolina. 2010. "Funcionalidad del marco y del fuera de campo en El hombre de al lado (2009)". Trabalho apresentado no II Congreso Internacional Artes en Cruce: Bicentenarios latinoamericanos y globalización, realizado entre 04 e 06 outubro 2010 na Facultad de Filosofía y Letras de la Universidad de Buenos Aires. Acessado em 14 março 2013. 
http://artesencruce.filo.uba.ar/sites/artesencruce.filo.uba.ar/ files/1-Cine-Soria.pdf.

Souza, Marcelo Lopes de. 2008. Fobópole. O medo generalizado e a militarização da questão urbana. Rio de Janeiro: Bertrand Brasil.

Tuan, Yi-fu. 2005. Paisagens do medo. São Paulo: Editora UNESP.

\section{FILMOGRAFIA}

Boquete, parte da série Productos caseros [performance filmada, online] Dir. Gaspar Libedinsky. Canal do artista no YouTube, Argentina, 2007. 4mins 19segs. https://www.youtube.com/watch?v=Db-IITg601s.

Cama adentro [filme] Dir. Jorge Gaggero. Aqua Films/Filmanova et al., Argentina/Espanha, 2004. 123mins.

Dos hermanos [filme] Dir. Daniel Burman. BD Cine/INCAA et al., Argentina, 2010. 105 mins.

El hombre de al lado [filme] Dir. Gastón Duprat e Mariano Cohn. Aleph Media/INCAA et al., Argentina, 2009. 110 mins.

El último verano de la boyita [filme] Dir. Julia Solomonoff. Travesia Productions/Domenica Films et al., Argentina/Espanha et al., 2009. 93 mins.

Germania [filme] Dir. Maximiliano Schonfeld. Pasto, Argentina, 2012. 75 mins.

La araña vampiro [filme] Dir. Gabriel Medina. Aeroplano Cine/No Problem Cine, Argentina, 2012. 92 mins.

Las viudas de los jueves [filme] Dir. Marcelo Piñeyro. Castafiore Films/INCAA et al., Argentina/Espanha, 2010. 122 mins.

Los salvajes [filme] Dir. Alejandro Fadel. La Unión de los Ríos/Hubert Bals Fund et al., Argentina/Holanda, 2012. 130 mins.

Luna de Avellaneda [filme] Dir. Juan José Campanella. Pol-Ka Producciones/INCAA et al., Argentina/Espanha, 2004. 143 mins.

¿Quién dice que es fácil? [filme] Dir. Juan Taratuto. Film Suez/Rizoma Films et al., Argentina, 2007. 108 mins.

Séptimo [filme] Dir. Patxi Amezcua. CEPA Audiovisual/K\&S Films et al., Espanha/Argentina, 2013. 88 mins. 
46 | NATALIA CHRISTOFOLETTI BARRENHA

Una semana solos [filme] Dir. Celina Murga. Tresmilmundos Cine, Argentina, 2008. 110 mins.

XXY [filme] Dir. Lucía Puenzo. Historias Cinematográficas Cinemania/Wanda Visión et al., Argentina/Espanha et al., 2007. 86 mins.

Recebido em 5-4-2017. Aceite para publicação em 28-9-2017. 